\title{
A New Phenolic Compound from Dendrobium longicornu
}

\author{
Jiangmiao Hu, ${ }^{\dagger, *}$ Weiwei Fan, ${ }^{\dagger, \dagger}$ Lu Zhou, ${ }^{\S}$ Youxing Zhao, ${ }^{\dagger}$ and Jun Zhou, ${ }^{\dagger, *}$ \\ ${ }^{\dagger}$ State Key Laboratory of Phytochemistry and Plant Resource in West China, Kunming Institute of Botany, \\ the Chinese Academy of Science, Kunming 650204, P. R. China \\ *E-mail:jzhou@mail.kib.ac.cn (J.Z.),hujiangmiao@mail.kib.ac.cn (J.H.) \\ ${ }^{\star}$ Graduate School of Chinese Academy of Sciences, Beijing 100039, P. R. China \\ ${ }^{\S}$ Spice Institute, Yunnan Agricultural University, Kunming 650051, P. R. China \\ Received June 8, 2010, Accepted August 28, 2010
}

Key Words: Dendrobium longicornu, Orchidaceae, Oxepine, Longicornuol B

The stems of several Dendrobium species (Orchidaceae) are used as "Shi-Hu" in traditional Chinese medicine mainly for the good of throat and immune ability. ${ }^{1-3} D$. longicornu belongs to Sect. Formosae of Dendrobium species and mainly distributed in southwest of China, ${ }^{1}$ and chemical research of this Sect. plant is not common. First chemical report of this species at $2004^{4}$ described five new phenolic compounds, and continual experiments of the species lead to the isolation of an interesting new phenolic compound (1) having an oxepine parent nucleus, together with three known compounds, trigonopol $\mathrm{A}(2), \beta$-sitosterol and daucosterol. To the best of our knowledge, it is the first time for the isolation of this kind of compound from Dendrobium species. This paper describes the isolation and structural elucidation of the new compound $\mathbf{1}$.

Compound 1 was obtained as a yellow amorphous powder, possessing a molecular-ion peak at $\mathrm{m} / z 283$ in its negative FABMS. The molecular formula of $\mathrm{C}_{16} \mathrm{H}_{12} \mathrm{O}_{5}$ was deduced from the negative HR FABMS ( $m / z 283.0604$ [M-H] $\left.{ }^{+}\right)$and its NMR data, indicating 11 degrees of unsaturation. The UV spectrum of $1\left(\lambda_{\max }(\log \varepsilon)\right.$ : 344 (3.9), 244 (4.2), 207 (4.4) nm) indicated an extended conjugaed system. The ${ }^{13} \mathrm{C}$ NMR spectrum of 1 exhibited 16 carbon signals, including one methoxyl, 7 methine and 8 quaternary carbons. The ${ }^{1} \mathrm{H}$ NMR spectrum of 1 exhibited three correlated aromatic methine signals at $\delta 7.41(1 \mathrm{H}, \mathrm{d}, J=$ $8.4 \mathrm{~Hz}), 6.56(1 \mathrm{H}, \mathrm{dd}, J=8.4,1.8 \mathrm{~Hz})$ and $6.62(1 \mathrm{H}, \mathrm{d}, J=1.8$ $\mathrm{Hz}$ ) indicating a 1,3,4-trisubstituted aromatic ring. Another set of three correlated aromatic atoms at $\delta 6.93(1 \mathrm{H}, \mathrm{d}, J=1.7 \mathrm{~Hz})$, $6.84(1 \mathrm{H}, \mathrm{dd}, J=8.4,1.7 \mathrm{~Hz})$ and $7.86(1 \mathrm{H}, \mathrm{d}, J=8.4 \mathrm{~Hz})$ suggested the presence of the second 1,3,4-trisubstituted aromatic ring. A proton signal at $\delta 9.93$ correlated with the carbon signal at $\delta 187.6(\mathrm{C}-12)$ in the HSQC spectrum indicated an aldehyde group. The aldehyde group was linked to a quaternary carbon (C-10), which in turn was connected to another quaternary carbon (C-11), as appreciated by their correlations [H-12/C-10, $\mathrm{C}-11]$ in the HMBC spectrum. These two quaternary carbons, two 1,3,4-trisubstituted aromatic rings and an oxygen constituted an oxepine nucleus. The observed correlations [H-12/C-9a, H-1/C-4a, C-11, H-9/C-5a, C-10] in the HMBC spectrum of 1 was in perfect agreement with the proposed structure. Therefore, compound 1 was determined as (Z)-7,11-dihydroxy-3-methoxy-10,11-dihydrodibenzo [b,f] oxepine-10-carbaldehyde and named as longicornuol $\mathrm{B}$.

The structure of compound 2 was confirmed to be trigonopol
A, ${ }^{5}$ a bibenzyl which was first reported from Dendrobium species by us recently. Other two known compounds, $\beta$-sitosterol and daucosterol, were elucidated by comparing with authentic compound by TLC means.

\section{Experimental Section}

General procedures. Melting points were measured on a XRC-1 micro-melting point apparatus (Beijing, China) and were uncorrected. Optical rotations were measured with a Horiba SEAP-300 spectropolarimeter. UV spectra were measured on a Hitachi UV-3210 spectrophotometer (Shanghai, China). IR spectra were measured with a Bio-Rad FTS-135 IR spectrometer (Richmond, CA) with $\mathrm{KBr}$ pellets. FABMS was obtained on a VG Auto Spec-3000 mass spectrometer (VG, Manchester, England). 1D and 2D NMR spectra were recorded on Bruker AM-400 MHz and DRX-500 spectrometers (Karlsruhe, Germany), with chemical shifts $(\delta)$ in ppm relative to trimethylsilane (TMS) as internal standard and coupling constants in hertz (Hz). Column chromatography was carried out on silica gel (200 $300 \mathrm{mesh}$ ) and TLC was carried out on plates precoated with silica gel (10 - $40 \mu \mathrm{m}$, Qindao Marine Chemical Ltd., Qingdao, PRC). Sephadex LH-20 was purchased from Amersham Biosciences.

Plant material. The stems of $D$. longicornu were collected in January 2004 from Xiaoshao of Kunming in Yunnan Province, P. R. China, and identified by Professor Hong Yu of Yunnan University. A voucher specimen (No. Zsh-1) was preserved at the State Key Laboratory of Phytochemistry and Plant Resource in West China, Kunming Institute of Botany, the Chinese Academy of Science, P. R. China.

Extraction and isolation. Extraction of the plant material $(4.5 \mathrm{~kg})$ with $95 \% \mathrm{EtOH}$ and evaporated under reduced pressure and then fractionated successively into $\mathrm{CHCl}_{3}$ soluble (76 g) and $n$ - $\mathrm{BuOH}$ soluble (73 g) fractions were reported previously. ${ }^{4}$ Got $\mathrm{CHCl}_{3}$ soluble $(70 \mathrm{~g})$ isolated into five fractions (A-E) and got $n$-BuOH soluble $(60 \mathrm{~g})$ isolated into six fractions $(\mathrm{I}-\mathrm{VI})^{4}$ were also reported. ${ }^{4}$ Fraction $\mathrm{B}(5.2 \mathrm{~g})$ from $\mathrm{CHCl}_{3}$ soluble was then applied to column chromatography over silica gel (petroleum ether-EtOAc, $3: 1, \mathrm{v} / \mathrm{v}$ ) to yield $\beta$-sitosterol. Fraction D $(3.0 \mathrm{~g})$ was applied to column chromatography over silica gel (petroleum ether-Acetone, 7:3, v/v) and purified further on Sephadex LH-20 (Ø $2 \times 120 \mathrm{~cm}, \mathrm{MeOH})$ to afford compound 1 
Table 1. ${ }^{1} \mathrm{H}$ and ${ }^{13} \mathrm{C}$ NMR assignments and two-dimensional NMR correlations of 1

\begin{tabular}{ccrc}
\hline Position & $\delta_{\mathrm{H}}($ mult,$J$ in Hz) & $\delta_{\mathrm{C}}($ mult $)$ & $\mathrm{HMBC}(\mathrm{H} \rightarrow \mathrm{C})$ \\
\hline 1 & $7.41(1 \mathrm{H}, \mathrm{d}, J=8.4)$ & $133.6(\mathrm{~d})$ & $\mathrm{C}-4 \mathrm{a}, 10$ \\
2 & $6.56(1 \mathrm{H}, \mathrm{dd}, J=8.4,1.8)$ & $108.8(\mathrm{~d})$ & $\mathrm{C}-3,4$ \\
3 & & $160.0(\mathrm{~s})$ & \\
4 & $6.62(1 \mathrm{H}, \mathrm{d}, J=1.8)$ & $100.5(\mathrm{~d})$ & $\mathrm{C}-2,3,4 \mathrm{a}$ \\
$4 \mathrm{a}$ & & $162.4(\mathrm{~s})$ & \\
$5 \mathrm{a}$ & & $157.2(\mathrm{~s})$ & \\
6 & $6.93(1 \mathrm{H}, \mathrm{d}, J=1.7)$ & $98.4(\mathrm{~d})$ & $\mathrm{C}-4 \mathrm{~b}, 6,7,8 \mathrm{a}$ \\
7 & & $156.3(\mathrm{~s})$ & \\
8 & $6.84(1 \mathrm{H}, \mathrm{dd}, J=8.4,1.7)$ & $114.2(\mathrm{~d})$ & $\mathrm{C}-5,8 \mathrm{a}$ \\
9 & $7.86(1 \mathrm{H}, \mathrm{d}, J=8.4)$ & $123.0(\mathrm{~d})$ & $\mathrm{C}-4 \mathrm{~b}, 9$ \\
$9 \mathrm{a}$ & & $118.5(\mathrm{~s})$ & \\
10 & & $118.1(\mathrm{~s})$ & \\
11 & & $163.2(\mathrm{~s})$ & \\
$11 \mathrm{a}$ & & $110.0(\mathrm{~s})$ & \\
12 & $9.93(1 \mathrm{H}, \mathrm{s})$ & $187.6(\mathrm{~d})$ & $\mathrm{C}-8 \mathrm{a}, 9,10$ \\
13 & $3.77(3 \mathrm{H}, \mathrm{s})$ & $56.1(\mathrm{q})$ & $\mathrm{C}-3$ \\
& & \multicolumn{3}{c}{}
\end{tabular}

(4 mg). Fraction III ( $2.1 \mathrm{~g})$ from $n$-BuOH soluble was then subjected to column chromatography over silica gel $\left(\mathrm{CHCl}_{3}-\mathrm{MeOH}\right.$, $20: 1, \mathrm{v} / \mathrm{v})$ and Sephadex LH-20 (Ø $1.7 \times 120 \mathrm{~cm}, \mathrm{MeOH})$ to give trigonopol A $(6 \mathrm{mg})$. Fraction IV $(12.0 \mathrm{~g})$ was subjected to column chromatography over silica gel $\left(\mathrm{CHCl}_{3}-\mathrm{MeOH}, 20: 1\right.$, $\mathrm{v} / \mathrm{v}$ ) and got daucosterol (42 mg).

Longicomuol B (1): Yellow amorphous powder, mp 96 - 98 ${ }^{\circ} \mathrm{C}$; UV (MeOH) $\lambda_{\max }(\log \varepsilon): 344$ (3.9), 244 (4.2), 207 (4.4) $\mathrm{nm}$; IR (KBr): $v_{\max } 3405,2956,2925,2854,1702,1646,1613$, 1496, 1467, 1438, 1377, 1309, 1264, 1202, 1135, 1061, 1029,
954, 894, 835, $813 \mathrm{~cm}^{-1} ;{ }^{1} \mathrm{H} \mathrm{NMR}\left(\left(\mathrm{CD}_{3}\right)_{2} \mathrm{CO}, 400 \mathrm{MHz}\right)$ and ${ }^{13} \mathrm{C}$ NMR $\left(\left(\mathrm{CD}_{3}\right)_{2} \mathrm{CO}, 100 \mathrm{MHz}\right)$ spectra data with chemical shifts $(\delta)$ in ppm, see Table 1; FAB MS $m / z(\%): 283$ [M-H] (100); HR FABMS 283.0604 [M-H] (calcd. for $\mathrm{C}_{16} \mathrm{H}_{11} \mathrm{O}_{5}$, 283.0606).

Acknowledgments. This work was financially supported by National Natural and Science Foundations of China (No. 30800090) and the Foundation of State Key Laboratory of Phytochemistry and Plant Resource in West China (P2008-ZZ25). The authors are grateful to Prof. Hong Yu of Yunnan University for identification of the plant material, Prof. Zi-hua Jiang of Lakehead University for amending of this manuscript and the members of the analytical group of the State Key Laboratory of Phytochemistry and Plant Resource in West China, Kunming Institute of Botany, for all of the spectral measurements.

Supplementary Material. FABMS (negative) and HR FABMS and $1 \mathrm{D}$ and 2D NMR spectra and of compound 1 can be available at supplementary material (Fig. S2-S8).

\section{References}

1. Jiangsu New Medicinal University, Dictionary of Chinese Medicines; Shanghai Scientific and Technical Publishers: 1986; p 586.

2. Committee of the Pharmacopoeia of China, Eds.; Pharmacopoeia of China, Part I; Chemistry and Industry Press: 2005; p 62.

3. Ye, Q. H.; Zhao, W. M.; Qin, G. W. In The Progress in Medicinal Chemistry; Peng, S. X., ed.; Chemical Industry Press: 2002; Vol. 3, p 113.

4. Hu, J. M.; Chen, J. J.; Yu, H.; Zhao, Y. X.; Zhou, J. Planta Medica 2008, 74, 535.

5. Hu, J. M.; Chen, J. J.; Yu, H.; Zhao, Y. X.; Zhou, J. Journal of Asian Natural Products Research 2008, 10, 647. 